\title{
Tecnogeografias: modulações nas ecologias e políticas cognitivas ${ }^{\star}$
}

\author{
Cleci Maraschin, ${ }^{I} \star \star ~ C a r l o s$ Baum, ${ }^{I}$ Fernando Teles, ${ }^{I}$ Renata Roos ${ }^{I I}$ \\ ${ }^{I}$ Universidade Federal do Rio Grande do Sul, Porto Alegre, RS, Brasil \\ ${ }^{I I}$ Faculdade Novo Hamburgo, Novo Hamburgo, RS, Brasil
}

\begin{abstract}
Resumo
Apresentamos uma pesquisa-intervenção concebida para analisar o jogo de localização "Um dia no Jardim Botânico", projetado para ser jogado por crianças e adolescentes no Jardim Botânico de Porto Alegre. Usando o jogo como instrumento de pesquisa, investigamos as articulações e percepções que ele ofereceu aos jogadores durante a exploração do espaço híbrido Jardim-jogo. Consideramos o campo empírico da pesquisa como um espaço tecnogeográfico que se configura localmente e constitui planos de consistência para a existência de objetos e ações e suas relações que são, ao mesmo tempo, ficcionais e reais. Assim, seguimos os efeitos do jogo tomado como uma experiência programada que participa do modo como percepções e explorações ocorrem nesse espaço público; bem como as modulações nas políticas e ecologias cognitivas que dai emergem. As oficinas nos permitiram acompanhar o processo de reconfiguração da política cognitiva desse espaço e repensar o conceito de experiência programada nos jogos de localização.
\end{abstract}

Palavras-chave: tecnogeografia; enação; jogo de localização; ecologias e políticas cognitivas.

\section{Technogeography: rearrangements in cognitive ecologies and politics}

\begin{abstract}
This is an intervention research intended to analyze a gps-based game named "A day at the Botanical Garden", designed for children and teenagers at Porto Alegre's Botanical Garden. By using the game as a research instrument, we meant to investigate the articulations of actions and perceptions it makes possible as players explore the hybrid garden-game space. Such empirical field is herein understood as a technogeographic space, locally arranged and able to offer patterns of consistency to the existence of objects and their relations, being simulteneaously real and fictional. We therefore consider the game as a designed experience that participates in the way perceptions and explorations emerge in a public space; as well as the cognitive ecologies and politics it might enable. By conducting a series of workshops with the game, we could track the rearrangements in players' cognitive politics and rethink the concept of designed experienced applied to gps-based games.
\end{abstract}

Keywords: technogeography; enacton; gps-based game; cognitive ecology politics.

\section{Introdução}

A ubiquidade com que as TIC - Tecnologias de Informação e Comunicação - povoam nosso cotidiano parece não mais nos espantar. Não simplesmente por se insinuarem de modo quase imperceptível em nossas vidas, mas principalmente, por nos acostumarmos a não questionar como configuram e transformam nossos espaços e territórios vividos. Desenvolvemos, como propõe Simondon (2008[1958]), uma relação ambivalente com os objetos técnicos, que ora são tomados como tendo uma função meramente instrumental - ampliando ou estendendo nossas capacidades - e ora concebidos como entidades estranhas capazes de corromper modalidades culturais tradicionais ou características humanas naturalizadas. Não é incomum encontrarmos o termo "impacto" para explicitar as relações entre humanos e máquinas o que demonstra que os objetos técnicos sejam continuamente tomados como estranhos àquilo que entendemos como cultura ou como humano.

Diante de proposições que separam os objetos técnicos da cultura, do social, este artigo se propõe a tomar outra direção, contemplando o engendramento

\footnotetext{
^ Fontes de financiamento e apoio: Cnpq, Edital Universal, Fapergs, Bolsas IC Prorext/Ufrgs, bolsas de extensão e apoio da Fundação Zoobotânica do Rio Grande do Sul.

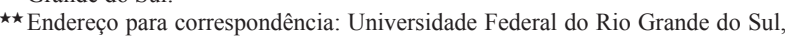
Instituto de Psicologia, Departamento de Psicologia Social e Institucional. Rua Ramiro Barcelos, 2600 - Santana. Porto Alegre, RS - Brasil. CEP: 90035-003. E-mail: cleci.maraschin@gmail.com, baum.psico@gmail.com, nandotelles@ gmail.com, renataroos@gmail.com
}

dos objetos técnicos em seus territórios cognintivos/ políticos - uma sociotécnica - que agencia movimentos de territorialização e de desterritorialização capazes de produzir outros regimes e políticas cognitivas.

A análise aqui apresentada toma como objeto de discussão a pesquisa-intervenção "Oficinando em rede: processos de aprendizagem e jogos de localização" realizada pelo Núcleo de Ecologias e Políticas Cognitivas (NUCOGS), a partir do desenvolvimento do jogo "Um dia no Jardim Botânico", ${ }^{1}$ projetado para ser jogado no Jardim Botânico de Porto Alegre. Consideramos o campo empírico da pesquisa - jogo no Jardim Botânico - como um espaço tecnogeográfico que se configura localmente e constitui planos de consistência para a existência de objetos e ações e suas relações. Partimos da ideia de que o modo como objetos técnicos se atualizam e se localizam em determinado território têm efeitos cognitivos e políticos nas formas de perceber e explorar

\footnotetext{
${ }^{1} \mathrm{O}$ jogo está acessível através da plataforma ARIS. Procedimentos para jogar:

I. Em um iPad, iPod e iPhone entrar na Apple Store e baixar o aplicativo ARIS

II. No aplicativo ARIS acionar aba "layable Anywhere".

III. Aguardar a lista de opções de jogos. Temos duas opções: a) Para quem está no Jardim Botânico - V0.31-SQ que significa a versão 3.1 que para jogar exige o deslocamento físico no Jardim Botânico e b) V0.31 que possibilita jogar sem deslocamento físico (versão utilizada para testagem fora do jardim).

IV. Ao escolher a V0.31 (para jogar sem estar no Jardim Botânico) acionar New Game e jogar.
} 
determinado espaço público, componente da paisagem urbana, engendrando sentidos e modulando ecologias e políticas cognitivas.

\section{Políticas Cognitivas}

A inspiração na Ecologia Cognitiva de Pierre Lévy (1993) e na Política Cognitiva de Kastrup (1999) evidencia um modo de compreender a cognição distinto do cognitivismo clássico. Enquanto o cognitivismo propõe descrever a cognição como aquilo que liga um sujeito a um objeto a ser conhecido, unindo duas realidades pré-existentes através de um sistema de regras invariantes ou de estruturas lógico-matemáticas de complexidade crescente, a ecologia cognitiva aposta numa compreensão da cognição como um ato que produz sujeito e objeto em uma perspectiva enativa, coemergente. $\mathrm{O}$ que significa dizer que considera a cognição a partir de uma concepção processual e inventiva, inserida nas práticas e nas políticas que a engendram e nos processos que lhe dão forma, reconhecendo sua dimensão espaço/ temporal/coletiva e de permanente transformação. Uma cognição territorializada que se reconfigura nas/pelas transformações no território no qual emerge e se modula.

Segundo Varela (1994, p. 11), “a informação deve aparecer não como uma ordem intrínseca, mas como uma ordem que emerge das próprias atividades cognitivas". Para o autor, a informação não está previamente depositada nos objetos cuja atividade cognitiva viria descobri-la, decifrá-la. Ela é efeito dos encontros que coengendram/inventam/reiventam sujeito e mundo. Nessa perspectiva, informações distintas são passíveis de serem constituídas a partir da transformação dos/nos encontros que passam a oferecer ocasiões de breakdowns, produzindo perturbações/desterritorizalizações no acoplamento sujeito-mundo. $\mathrm{O}$ resultado de um breakdown/desterritorialização é sempre imprevisível, mais próximo da criação do que da repetição invariante.

Com isso, o que se obtém nesses encontros são fluxos híbridos (LATOUR, 1994) compostos por sujeitos, técnicas, objetos e instituições. Pesquisar a cognição nessa abordagem implica acompanhar, através de suas práticas, o modo como uma inteligibilidade se constrói em uma ecologia cognitiva.

Definida em sua processualidade, uma ecologia cognitiva é também política pois varia dependendo do arranjo/relação entre seus atores, que podem ser humanos e não-humanos, individuações singulares e coletivas. Em cada um desses arranjos são constituídas e distribuídas modalidades de relações, assim como são negociadas as possibilidades de ação de cada ator. As soluções produzidas podem ser as mais diversas, mas sempre se tratará de repartir, de arranjar, de definir direitos e prescrever deveres (STENGERS, 2002).

Uma abordagem política permite criar um espaço problemático no qual a questão do ordenamento dessa ecologia pode ser acompanhado/problematizado. Reconhecemos no termo política uma referência à participação ativa em uma coletividade heterogênea, ao estabelecimento de associações entre elementos distintos e à constituição do(s) contexto(s) onde tais associações podem ocorrer.

Desta forma, o convite para explorar o espaço do Jardim Botânico por meio de um jogo de localização, potencialmente, abre margens para a ação, para a intervenção e para a expressão que produzem deslocamentos em relação as lá já existentes. Assim, o jogo pode ser pensado como um ator em uma ecologia político-cognitiva.

\section{Jogos de Localização}

Os chamados jogos de localização se desenvolveram a partir do encontro entre os videogames e as mídias locativas baseadas em GPS (Global Positioning System) ou sistema de triangulação de sinal "telefônico" (LEMOS, 2010). Trata-se de uma modalidade de jogos nos quais diversos jogadores podem compartilhar estratégias de colaboração ou competição que se desenrolam utilizando um necessário acoplamento entre software e território.

O importante em uma pesquisa utilizando videogames - ou jogos de localização - é compreender os modos de habitar o espaço do jogo, os mecanismos utilizados para criar sentido e como esses sentidos e experiências emergem. Squire (2006) propõe que os jogos possam ser entendidos como uma experiência programada na qual o design do jogo modula a experiência do jogador, mas não a determina. As regras definem as condições de possibilidade da experiência, como uma espécie de território no qual se transita. Um território arquitetado que se revela na medida em que é explorado.

A importância do processo do jogo dá a reconhecer que as regras do mesmo não são somente restritivas, mas podem ser abertas e flexíveis. Desta forma, os designers do jogo criam um campo de possíveis, mas em última instancia, são os jogadores que decidem quais ações serão realizadas (BAUM, 2012). Partindo desta perspectiva, a experiência do jogador é uma interação entre o planejamento do game design e as ações efetivamente realizadas por ele no jogo. Deste modo, Squire (2006) refere que videogames não devem ser entendidos como códigos estáticos que precisam ser lidos ou interpretados como se existisse uma "essência do jogo", um único (e correto) modo como ele deve ser jogado.

Segundo Mont'Alverne (2012), nos jogos de localização, o território é utilizado de maneira lúdica, permitindo novas espacializações a partir da inserção de tecnologias móveis de comunicação. Para ele, são três as características básicas que descrevem tais jogos. A primeira consiste na extensão do jogo ao mundo real, tornando-os uma versão ampliada dos jogos clássicos de tabuleiro ou videogames. A segunda, na mistura entre realidade e ficção, o que coloca em contiguidade elementos reais e virtuais, criando narrativas com forte sensação de realidade. A terceira característica, advinda das duas anteriores, confere a esses jogos uma modalidade de experiência que se produz no prolongamento entre o real e o virtual, por contiguidade, configurando um exemplo consistente de um híbrido tecnogeográfico. 
Jogar um jogo eletrônico qualquer consiste em interagir com regras reais em um mundo ficcional (JUUL, 2011, p. 1). Semelhante mistura real-ficional pode ser estendida para pensar um jogo de localização, pois também se trata de uma composição entre a jogabilidade e a narrativa. A jogabilidade é entendida como sendo as condições e modos de interação oferecidas ao jogador pelo ambiente do jogo e as reações desse ambiente em função de suas escolhas (SATO; CARDOSO, 2008). Diferentemente de um jogo que se desenrola somente em uma tela, em um jogo de localização temos uma coordenação entre território e o que se passa na tela de um dispositivo móvel. O jogo se processa pelo deslocamento em um território que pode ser lido simultaneamente no espaço da tela do dispositivo móvel. O espaço do jogo constitui esse composto real-ficcional na medida em que um jogo de localização somente é jogado no momento em que o espaço está agenciado com objetos técnicos.

Neste trabalho, referimo-nos ao jogo "Um dia no Jardim Botânico" como um jogo de localização devido à tônica atribuída ao espaço tecnogeográfico do Parque Jardim Botânico para sua jogabilidade. Trata-se de um jogo de coleta, no qual os jogadores são convidados a encontrar e a plantar sementes virtuais, com o intuito de preservação das coleções existentes no Jardim Botânico. Para realizar o desafio, necessitam localizar no território as sementes e os itens necessários para seu plantio (balde, água e pá), deslocando-se com um dispositivo móvel. Vence essa primeira fase quem conseguir plantar ao menos 05 sementes virtuais nos locais próprios especificados no Jardim. Ultrapassar o desafio equivale a uma maior pontuação final. No trajeto, existem atores digitais que podem auxiliar ou dificultar esses objetivos, trazendo informações sobre as sementes, as coleções, modos de plantio e a estrutura do Jardim. Logo, o espaço do parque desempenha papel seminal para que o jogo possa ser jogado, ou seja, a fim de que as modulações cognitivas que se dão neste sistema de objetos e ações sejam enatuadas pelos atores/jogadores/interventores.

O jogo contempla três missões principais. A primeira delas, que denominamos de turorial - por explorar as ações necessárias para jogar -, consiste em encontrar um jardineiro (ficcional) o qual solicita ao jogador que encontre uma pá (também ficcional) e lhe devolva. Ao cumprir essa primeira missão, abre-se a segunda missão que consiste em plantar. Para tal necessita encontrar um botânico (ficcional) que lhe indica os itens e procedimentos necessários para plantar uma muda de orquídea (necessita encontrar um regador (ficcional) e enchê-lo de água (ficcional) no lago (real), além de coletar a muda de orquídea (ficcional) no viveiro de plantas (real) e plantá-la no orquidário (real). Ao plantar a semente de orquídeas, abre-se a terceira missão que consiste em plantar outras sementes (ficcionais) nas áreas específicas do Jardim Botânico (reais). A missão pode ser dificultada ao encontrarem um lagarto (ficcional) que exige para continuar o jogo que os jogadores lhe entreguem um dos itens coletados. A cada semente plantada corresponde uma quantidade de pontos que varia de acordo com a localização da região da família das plantas no Jardim Botânico.

A ideia de aliar um elemento lúdico, interacional e tecnológico ao espaço do Jardim Botânico já carregado de significados científicos e educativos advém do fato de que os videogames comportam, como já mencionamos, duas dimensões: consistem em regras reais através das quais os jogadores interagem agregando uma narrativa ficcional. Ganhar ou perder um jogo consiste em um evento real. Entretanto, ganhar um jogo negociando com um lagarto, por exemplo, indica sua dimensão ficcional. No espaço tecnogeográfico as fronteiras entre ficção e real são configuradas e reconfiguradas na medida em que se joga de maneira performativa.

\section{Um dia no Jardim Botânico}

Durante o segundo semestre de 2013, realizamos oficinas com crianças e jovens a título de testar a primeira versão do jogo. No total, foram realizadas 07 oficinas com participantes ${ }^{2}$ advindos de dois projetos socioeducativos da cidade de Porto Alegre. A primeira oficina ocorreu com grupo vinculado ao Programa da Saúde da Família da Unidade Básica de Saúde da Vila Viçosa, denominado de Oficina Linguagens da Cidadania (OLC) e as seis restantes com ONG Paz e Mel localizada no bairro Partenon. Ambos projetos acolhem crianças e adolescentes no contra-turno escolar. A primeira oficina foi realizada com 16 crianças da OLC, sendo que além do jogo foram convidados a resolver desafios com os tablets. Decorrente dessa oficina, avaliamos ser necessário organizar um tutorial para o jogo, introduzindo os principais comandos necessários para o manuseio do tablet ao longo das partidas. Posteriormente, com o segundo grupo, antes da visita ao Jardim Botânico realizamos uma oficina na sede da ONG Paz e Mel para explorar o tablet e o Google Maps. Após, realizamos mais cinco oficinas no Jardim Botânico com as 20 crianças da ONG. Sendo que em cada uma delas convidamos quatro crianças para jogar. Elas jogavam em duplas acompanhadas pelos oficineiros.

Para nossa discussão, vamos recuperar dessas oficinas algumas das experiências dos participantes em relação as suas questões, comentários, interesses e estranhamentos sobre esse espaço tecnogeográfico. Focamos em tais elementos, pois um modo interessante de estudar o processo de distribuição nas políticas cognitivas é seguir a principal função da cognição que, segundo Varela, Thompson e Rosch (2003), consiste em colocar as questões pertinentes às contingências vividas. Assim, as questões e o estranhamento dos participantes indicam um mapeamento inicial das modulações das políticas cognitivas nos modos de explorar o jogo como um novo espaço. Ou seja, tomamos os estranhamentos e as questões dos jogadores como indicadores de deslocamentos na política cognitiva habitual.

Todos os participantes assinaram um TCLE. Os nomes utilizados no artigo são iniciais de pseudônimos. 


\section{Paisagem, espaço e cognição}

Para acompanhar as modulações que relatamos a seguir, é importante considerar a distinção de Santos (1997) entre paisagem e espaço. Para o autor:

A paisagem é o conjunto de formas que, num dado momento, exprimem as heranças que representam as sucessivas relações localizadas entre homem e natureza. O espaço são essas formas mais a vida que as anima (SANTOS, 1997, p. 66).

O Jardim Botânico pode ser tomado como paisagem se considerado em sua forma. No início do século XX o local onde atualmente se encontra era denominado de Várzea de Petrópolis, uma área de terra irregular, oscilante entre pequenos morros e alagados. Atualmente, compreende 39 hectares de terra povoados por 653 espécies arbóreas, abrigando aproximadamente 3 mil exemplares de árvores somados a outra coleção de cerca de 3 mil exemplares de plantas envasadas, um banco de germoplasma e um de sementes. A principal finalidade do Jardim Botânico é o estudo e a conservação de espécies vegetais nativas do Rio Grande do Sul, especialmente aquelas ameaçadas de extinção.

$\mathrm{Na}$ presente discussão para além de paisagem, tomaremos de empréstimo a noção de espaço de Santos (1997) a fim de tratar o Jardim Botânico em sua tecnogeografia. Com esse intuito, buscamos identificar as modulações tecnogeográficas que ocorrem nas ecologias e políticas cognitivas com a conexão de um novo objeto técnico agregado ao espaço e seus efeitos nos modos de exploração dos visitantes, ou seja, nos modos como esses visitantes apreendem o espaço. O espaço é definido pelo autor como "um conjunto indissociável de sistemas de objetos e de sistemas de ações" (SANTOS, 1997, p. 12) sendo, portanto, um espaço vivido.

A ideia de espaço vivido se aproxima da noção de cognição enativa de Varela (1994) na qual o espaço resulta do movimento. Na teoria enativa, como comentamos acima, tanto o mundo como a cognição são concebidas como efeito de coordenações sensório-motoras que se efetivam em acoplamento em determinada circunstância. Ao contrário da teoria da representação, onde a cognição é compreendida como uma captura de objetos préexistentes em um mundo que existe independentemente de um sujeito que o conhece, na cognição incorporada cognição e mundo surgem concomitantemente em uma experiência ativa e ativada.

Cognição e espaço, portanto, não existem de modo independente. Voltando a Santos (1997), o espaço constitui-se como um conjunto de objetos organizados e acionados segundo uma lógica. Essa lógica da instalação das coisas e da realização das ações se confunde com a lógica da história, à qual o espaço assegura a continuidade. É nesse sentido que podemos afirmar, com o autor, que a síntese realizada através do espaço não implica uma harmonia pré-estabelecida. Cada vez que se produz uma nova síntese, cria-se uma nova unidade.

Podemos radicalizar a noção de espaço traduzindo a ideia de síntese/unidade pela de rede sociotécnica, de Latour (1994). Essa tradução, em nosso entender, é interessante pois, para esse último autor, a noção de rede para o estudo da sociotécnica é considerada "mais flexível do que a noção de sistema, mais histórica do que a de estrutura, mais empírica do que a de complexidade" (LATOUR, 1994, p. 9). A noção de rede refere-se a articulações, mediações, alianças, movimentos, de modo vivo e não estagnado ou fixo. O que significa dizer que estamos em agenciamento, conectados, produzindo vínculos que nos trazem certa estabilidade de acordo com os acoplamentos, mais ou menos duráveis, mas nunca previsíveis e determinados. Assim, há uma dimensão heterogênea na rede, provisória, criativa, instável, conectante e produtiva. Não há um modelo a priori, uma essência, capaz de estabelecer, de antemão, os atores, os efeitos, as performances, as traduções, as recalcitrâncias. No estudo de uma rede sociotécnica o ponto de partida é estabelecer um marco zero no peso das ações dos atores. Desse modo, dá-se oportunidade para que as diferenças apareçam, já que elas não são dadas de antemão, mas construídas na contingência operativa da própria rede.

Embora possamos abrir uma controvérsia do quanto a noção de rede de Latour se alinharia ou não à noção de paisagem de Santos - o que pressuporia homem e natureza em relação, mas de alguma maneira precedentes ontologicamente -, tal debate, embora interessante, fugiria aos propósitos deste artigo. O que aqui nos interessa salientar, em consonância com Latour (1994) é que não façamos apenas o estudo de como o sujeito construiu o objeto, mas também de como o objeto faz o sujeito. Neste sentido, existe um pressuposto de reciprocidade ao considerar todos os atores, sejam eles humanos e não humanos, como capazes de exercer agência na rede. Afinal, não são apenas os sujeitos que agem, mas os objetos também possuem poder de ação, transformação, entendidos como quase-objetos, híbridos, capazes de produzir modos de ser e existir. Assim, o que o espaço agencia não seria uma nova unidade mas uma rede tecnogeográfica.

Agregando a contribuição dos autores até agora citados, chegamos à ideia de espaço como híbrido tecnogeográfico não substantivo, que se configura mais como um plano de sustentabilidade processual/ maquínico no qual objetos, ações e modos de conhecer ganham consistência e agência - modos de existência -, consolidando lógicas e políticas. Essa noção nos afasta da ideia de ambientalismo, uma vez que o próprio sujeito não é independente e se constitui em espaços de modo situado e encarnado.

Ao indagarmos sobre os modos de conhecer e de perceber que emergem em determinado espaço tecnogeográfico, nos colocamos a questão da cognição enativa como uma produção de si que se faz de modo situado e incorporado. Assim, vinculamos o conceito de espaço tecnogeográfico ao de ecologia cognitiva como já escrevemos anteriormente:

A ecologia cognitiva constitui um espaço de agenciamentos, de pautas interativas, de relações constitutivas, no qual se definem e redefinem as possibilidades cognitivas individuais, institucionais e técnicas. É nesse espaço de 
agenciamentos que são conservadas ou geradas modalidades de conhecer, de formas de pensar, de tecnologias e de modos institucionais de conhecimento (MARASCHIN; AXT, 1998, p. 2).

Desse modo, um objeto técnico se agencia segundo forças originadas em diferentes escalas, mas que se realiza em um lugar, cujas mesmas forças modulam ao longo do tempo. O trabalho de acompanhar uma política cognitiva implica, precisamente, colocar em um mesmo plano e ordenar as relações entre atores heterogêneos, acomodando essa diversidade e estabilizando ajustamentos e negociações.

Cabe agora pensar as modulações na ecologia cognitiva ao se incluir na rede de atores de determinado espaço um jogo de localização.

\section{Breakdown e a articulação com o objeto técnico}

Um primeiro estranhamento causado pelo jogo foi explorar o território do Jardim através do mapa disponibilizado na tela do dispositivo móvel. O mapa apresenta o deslocamento do jogador através de um ponto luminoso que vai modificando sua posição de acordo com a movimentação do jogador. No início do jogo está visível no mapa a localização do jogador, bem como o primeiro objeto a ser constatado, no caso, o Jardineiro. Para jogar é necessário articular o caminhar no Jardim com a leitura do deslocamento do "avatar" na tela do Tablet, como mostra o extrato abaixo:

- Pesquisador: Vocês estão bem aqui onde está esse ponto azul. Ficam girando e olhando ao redor. Ric diz: É para lá (apontando a região das Plantas Medicinais - na direção oposta na qual se encontra o Jardineiro). Ric: Eu acho que é para lá. É para lá, né?. Pesquisador: Se vocês tão aqui e têm que achar o Jardineiro [...] (indica que usem o mapa na versão satélite, pois ele contém as edificações). Pesquisador: E agora? Ric: Tá andando em círculo! avisa ao colega que segura o Tablet. [...]_Nat:_Se eu vou para o lado ele vai para frente, se eu continuo indo para a frente ele muda (descrição vídeo de 08/11/2014).

O estranhamento causado pela necessidade de sincronização entre mapa e território foi bastante frequente no início do jogo. De tal sorte que entre as experiências do primeiro e do segundo grupos incluímos um tutorial e desenvolvemos com os participantes do segundo grupo uma oficina de leitura de mapas. Com o tutorial e com a oficina de leitura de mapas foi possível propiciar uma experiência de conexão entre mapa e jogador, de modo a propiciar uma familiaridade com essa conexão.

Procurar uma localização com um mapa virtual que atualiza a posição do caminhante conforme seu deslocamento, agrega novas operações à experiência de utilização de um mapa fixo. O movimento do avatar apresentado na tela do tablet necessita estar coordenado com o movimento de andar para que se produza uma ação congruente entre ambos. Nesse sentido, além da leitura

Fractal, Rev. Psicol., v. 28 - n. 2, p. 213-220, 2016 dos mapas e sua correspondência ao território há, ainda, o desafio de sincronizar, tempo, espaço e movimento, para poder adentrar à jogabilidade do jogo.

Anecessidadedoestabelecimento dessascoordenações ocasiona breakdowns que podem ser entendidos como quebras, rupturas, em algo já consolidado, habitual, conhecido, exercício que convoca a invenção. Ou seja, é necessário produzir uma compatibilidade entre duas ordens de magnitudes distintas o que para Simondon (2013) caracteriza a invenção.

A experiência propõe que se preste atenção a si e ao contexto, arregimentando outra atenção e consciência de si e de mundo, que possa reterritorializar a experiência de espaço, corpo, tempo. Ou seja, se no dia a dia usamos de atenção e consciência para nos deslocarmos, essas operam sob uma espécie de transparência, pois não somos chamados a pensar sobre o que estamos fazendo a cada passo. Ao observar, através da tela do tablet uma projeção dessa sincronia, o jogo convoca para uma consciência e atenção de si diferentes. Pelo menos nesses primeiros momentos de aprendizado, em que o jogo ainda causa estranheza e breakdowns.

\section{Explorando e recriando a partir da imprevisibilidade}

Uma conexão interessante foi o fato de que outros visitantes e trabalhadores do Jardim Botânico fossem considerados fonte de informação para o jogo. Deste modo, não somente os objetos ficcionais programados são atores do mesmo. Os encontros com outros seres no jardim possibilitam uma grande abertura ao jogo, pois não podem ser programados, acontecem ao acaso, implicando certa improvisação entre o que se mostra possível de estabelecer relações com o jogo. Essa margem de incerteza é capaz de produzir outra atenção, outra sensibilidade com o que num passeio comum passaria desapercebido, invisível.

- Na primeira oficina, os participantes foram convidados a realizar alguns desafios, como encontrar e fotografar um formigueiro. Uma participante perguntou a um rapaz que passava perto: - Tu trabalha aqui? Ao que ele respondeu: - Trabalho sim! - Tu sabe dizer onde tem formigueiro? Ele responde que não, e elas logo perguntam a outra moça que está vindo pelo mesmo caminho. A moça responde que não sabe, então pergunto: - E nem para indicar, algum lugar mais provável? A moça aponta para uma parte mais abaixo do Jardim, e as meninas saem correndo pelo gramado. Saio atrás, meio doida da vida. Que experiência! As meninas encontram pequenos formigueiros. A menina que estava comigo se demorou mais, quando encontramos, eu digo: - Mas é mesmo formigueiro? - É sim Sôra! (diário de campo 28/07/2013).

Um efeito interessante foi a curiosidade que alguns elementos do território causavam. Esses encontros, por vezes levavam os participantes a incluir um subobjetivo ao próprio jogo, ou chegavam a interrompê-lo para explorar outras características do Jardim Botânico. Enquanto 
a maioria dos jogos digitais oferece um conjunto de problemas bem definidos e a maior parte das simulações sacrifica alguns elementos realistas, a fim de permitir que o jogador acompanhe os objetivos com mais clareza (deixando o volume de variáveis gerenciável), em jogos de localização, como "Um Dia no Jardim Botânico", é comum que alguns jogadores mesclem objetivos do jogo com outras funcionalidades do próprio local, perguntando a transeuntes sobre aspectos ficcionais do jogo (KLOPFER, 2008). Nossos jogadores questionaram se as placas do parque também indicavam o caminho do jogo, se as sementes que deveriam procurar estavam escondidas entre as árvores ou eram ficcionais. As redes de relações que compõem o jogo permanecem imprecisas sendo necessário um contínuo trabalho de articulação que não se fecha em um conjunto de regras. Tal como destacamos acima, a capacidade de colocar as questões pertinentes a cada instante é um dos elementos cruciais da experiência com um jogo de localização que permite a exploração dessa capacidade de fazer distinções, tal como podemos observar nos extratos abaixo:

- Ao fotografar os cisnes do lago, ficaram intrigados e discutiram o passeio inteiro se eram cisnes, gansos, ou cisnes pretos (diário de campo 28/07/2013)

- Havia uma grande poça d'água ao final da ponte sobre o lago. Tai e Gab tentaram passar para o outro lado, mas a poça d'água os impedia. Após algumas tentativas, Tai disse: - Vem, vamos achar outro caminho. Saíram correndo até encontrar outro modo de chegar ao outro lado da poça (diário de campo 13/11/2013).

- Ao chegar ao lago, coletaram a água e o alarme soou. Dai cutucou Ias, mostrando-lhe que havia peixes grandes no lago. Elas me perguntaram: - Que tipo de peixe é esse? Ao que respondi que achava que eram carpas (diário de campo 27/11/2013).

- A dupla que acompanhava por vezes corria por outros locais do Jardim e diziam: Olha, o que é aquilo lá? Certo que lá tem coisa (diário de campo 13/11/2013).

Esses e outros extratos revelam o interesse dos participantes pelos conteúdos do Jardim. Perguntas sobre, o que é botânica?, qual a diferença de um Butiá e uma Palmeira?, como vive uma orquídea?, entre outras, foram muito frequentes. Mas o que gostaríamos de reforçar é que a relação com o território confere ao jogo uma abertura não programável, o que amplia as condições de experiência em um jogo de localização:

- Um fato inusitado aconteceu quando as meninas procuravam o Botânico ficcional do jogo, caminhando na direção de sua localização marcada no mapa. Ao levantarem os olhos da tela, se deparam em frente do Sr. Daniel que no jogo foi fotografado como Botânico. As duas levaram um susto e disseram praticamente ao mesmo tempo: - Ele existe!. Foi uma gargalhada geral, pois todos nós nos surpreendemos (diário de campo 27/11/2013).

Questões que comparavam jogos digitais e jogos de localização também mostram a diferença dos elementos e ações que os constituem os espaços de cada um. Essas distinções foram objeto de questionamento e novas distinções, como observamos nos excertos abaixo:

- Gui pergunta: Se eu tô fora do Jardim Botânico e eu tô na minha casa, como jogo ele? O que a gente faz com ele? (video 06/11/2013).

- Dai que jogava pela segunda vez foi convidada a explicar para os colegas como se jogava o jogo. Ela diz: Aqui o mouse é a gente e a tela é tudo isso [indicando o Jardim]" (diário de campo 27/11/2013).

O espaço de cada jogo é composto, como acima discutido, por diferentes redes sociotécnicas que constituem e modulam objetos e ações. O caso mais interessante dos jogos de localização parece ser um espaço onde objetos e regras reais se conectam com objetos ficcionais. A questão recorrente nesse sentido foi a pergunta: Por que não plantar de verdade? Um dos mais desconcertantes momentos do jogo, tanto para os jogadores como para os pesquisadores, foi experimentar a articulação entre objetos ficcionais e reais no jogo. Alguns excertos das oficinas mostram o estranhamento causado por habitar esse inusitado espaço no qual essas misturas coexistem:

- Ao final de cada oficina realizávamos uma roda de conversa. A pesquisadora pergunta o que acharam. Van responde que achou difícil. A pesquisadora pergunta porquê. Van explica que quase não achou nada. Não achou a tartaruga. Outro menino fala que viu a tartaruga. Outro, que viu 5 tartarugas. Van se refere às tartarugas do jogo [ficcional], enquanto os meninos mais jovens se referem à tartaruga do lago. Van retoma o turno, xingando Tal. Diz que não achou quase nada e que se metia no mato. Que era bem legal (vídeo 28/07/2013).

- [o jogo avisa que encontraram a pá]. Nat olha em baixo do carro procurando a pá. Pesquisadora: -a pá é a do jogo... vocês já tem [...] [mostra o inventário] e continua: - Será que o jardineiro tá de verdade ou tá no jogo? Nat diz estar no jogo mas procura ao redor [...] (descrição vídeo de 08/11/2014).

- Tiraram algumas fotos no estacionamento, fotografaram uma pá que estava no canteiro e pensaram ser a do jardineiro. Dissemos que não seria aquela pá, mas uma pá virtual (diário de campo 13/11/2013).

- Die perguntou sobre as sementes. Dissemos que não teríamos de plantar sementes de verdade, apenas de brincadeira, no jogo. Ela aparentou certa decepção, dizendo que seria mais tri plantar as sementes de verdade (diário de campo 13/11/2013). 
- Em vez de plantar verdadeiramente a gente vai plantar pelo jogo (Dai explicando aos colegas) (transcrição de áudio 27/11/2013).

Os excertos anteriores mostram o inusitado de viver em um mundo que conecta objetos ficcionais e reais. Um espaço que nos disponibiliza objetos ficcionais dependendo de nossas interações. Uma tecnogeografia na qual os encontros fazem parte do jogo e, por seu inusitado, causam desconcerto e questões aos modos usuais de perceber e interagir com o espaço. Um espaço que lança questões à cognição que de acordo com Varela (1994) inclui a invenção de problemas. A cognição inventiva se constitui a partir da problematização, dos breakdowns, que constituem rupturas no fluxo cognitivo habitual e, por isso, busca criar novas soluções.

Ao enriquecer com elementos ficcionais os espaços nos quais se realizam, os jogos de localização se constituem em uma estratégia para explorar a capacidade do jogador de complexificar a produção e a resolução de problemas através da ludicidade, da invenção. A jogabilidade está embutida no espaço concreto, que por sua vez é impreciso e irregular, podendo apresentar surpresas, desafios, novas modulações e descobertas. Segundo Klopfer (2008), jogos de localização produzem no jogador uma expectativa de que o jogo incorpore, ao menos em parte, a imprecisão do mundo cotidiano. Em alguns momentos durante o jogar, surgiram desafios inesperados como no extrato do diário de campo $13 / 11 / 2013$, acima comentado. A dupla de crianças estava em busca de um item e ao passarem sobre uma ponte para atravessar o lago puderam observar que a outra extremidade da ponte estava alagada. Este fato provocou que os jogadores tivessem que buscar um caminho alternativo, que não havia sido previsto nem mesmo pelos designers do jogo. O caminho obstruído modificou as possibilidades dos jogadores, de forma que certas estratégias se tornaram impossíveis ou mais ou menos eficientes, o que demonstra que o aprendizado acontece sempre em uma relação entre o jogador e o ambiente (incluindo aqui o local, o ambiente digital criado pelos designers e as relações com os outros participantes).

\section{Espaços como invenções}

$\mathrm{O}$ jogo que estamos desenvolvendo e as experimentações iniciais que realizamos nos permitem ampliar a ideia de espaço como sendo somente relativa ao conjunto de relações entre objetos em determinado território. As oficinas têm possibilitado vivenciar um espaço mutante e mestiço que ao se modificar modula o modo como distinguimos os objetos, percebemos relações e aquilo que definimos como realidade. Um espaço vivido que se individua na experiência, espaço enatuado.

Os jogos de localização possibilitam também a exploração do conceito de experiência programada. No jogo, os elementos ficcionais/digitais transformam a relação com o espaço anterior ao jogo, que poderia já ser conhecido pelo jogador, mas que vai, gradualmente, conforme o jogo avança, assumindo novas configurações. O design do jogo, por sua vez, inclui a possibilidade do jogador inventar problemas mais do que definir problemas com contornos de respostas precisas. A participação do jogador na construção da experiência também é ampliada, uma vez que o conhecimento, tanto prévio quanto construído in situ, pode modificar as condições de possibilidade para a invenção. Por fim, participação do ambiente concreto (real) na jogabilidade programada complexifica e amplia as possibilidades de interação com o jogo, incluindo diversos aspectos imprevistos pelo designer, dos quais os jogadores podem lançar mão, como informação de transeuntes e caminhos não mapeados. Tais aspectos contribuem para o enriquecimento da experiência do jogo, que é tradicionalmente definida por suas regras.

Nessa experiência, o espaço foi vivido como híbrido tecnogeográfico não substantivo, no qual objetos antes distinguidos como reais, passam a fazer parte da ficção uma vez que são convocados pelos jogadores a participar do jogo. Do mesmo modo, o jogo faz com que objetos do Jardim adquiram consistência e interesse na exploração, tornando-os objetos passíveis de realização, como a vontade de plantar "de verdade".

Como vimos, a narrativa fictícia que deflagra o problema central do jogo não encontrou barreiras no espaço "real" do Jardim Botânico. Os conflitos, quando surgiram, foram negociáveis, principalmente quando a aprendizagem do jogo exigia que os jogadores compusessem o mapeamento lúdico da tela do tablet com o território que exploravam com as próprias pernas.

Nessas ocasiões, regras virtuais foram testadas no ambiente "real", o corpo foi transformado em mouse, os funcionários em informantes e os itens virtuais em objetos concretos capazes de produzir efeitos relevantes para o espaço. Se a técnica parece encerrar um acordo pronto, uma estabilização fria a qual apenas se delega uma tarefa, podemos perceber que ao invés de meramente intermediar uma ação, o jogo como técnica mediou outros acordos que não existiam naquele espaço antes de sua chegada. À distribuição das sementes, jogo e jogadores acrescentaram outras propriedades a cada ponto do Jardim com base na mecânica do jogo.

Lugares que um visitante não jogador talvez não notasse, imediatamente, se transformaram em pontos de passagem obrigatória pelos jogadores que os perceberam mediados; não apenas por seu valor na narrativa que define sua relevância para o meio ambiente, mas também por sua participação no modo como o jogo organizava e distribuía relevâncias ao redor do Jardim. A articulação entre objetos técnicos - tão presentes em nossa cultura atual, como destacamos de início -, com o Jardim Botânico - que muitas vezes é tomado somente com um espaço contemplativo, é capaz de produzir um espaço sociotécnico vivido, no qual os jogadores podem produzir ações e invenções, mudando o status de visitantes para jogadores e o jardim de paisagem para espaço. O jogo de localização promove um maior enervamento entre o jardim e a vida na cidade, ou seja, o jardim se atualiza como um modo de viver na cidade. 
Apostamos na ideia de que experiências como essa põem à mostra o que já acontece em nossas cidades nas quais interagimos com objetos técnicos, como um GPS para encontrar um caminho; um caixa eletrônico para fazer nossas operações bancárias; um telefone celular para saber a previsão do tempo. Mas para além de todos esses usos, o jogo de localização pode ser um meio lúdico de apropriação e de questionamento das cidades que estamos construindo. Uma tecnogeografia, uma ecologia cognitiva e política que modula o modo como distinguimos e compomos realidade e ficção, para construir outros modos vivíveis nesses emaranhados sociotécnicos.

\section{Referências}

BAUM, C. Sobre video game e cognição Inventiva. 2012. Dissertação (Mestrado)-Universidade Federal do Rio Grande do Sul, Porto Alegre, Brasil, 2012.

JUUL, J. Half-real: video games between real rules and fictional worlds. Cambridge: MIT, 2011.

JARDIM BOTÂNICO DE PORTO ALEGRE. Fundação Zoobotânica do Rio Grande do Sul. Website institucional. Disponível em: <http://www.jb.fzb.rs.gov.br/>. Acesso em: 28 abr. 2014.

JARDIM BOTÂNICO DE PORTO ALEGRE. Verbete da Wikipédia. Disponível em: <http://pt.wikipedia.org/wiki/ Jardim_Botânico_de_Porto_Alegre>. Acesso em: 28 abril 2014.

KASTRUP, V. A invenção de si e do mundo: uma introdução do tempo e do coletivo ao estudo da cognição. Campinas, SP: Papirus, 1999.

KLOPFER, E. Augmented learning: research and design of mobile educational games. Cambridge, MA: MIT, 2008.

LATOUR, B. Jamais fomos modernos: ensaio de antropologia simétrica. Rio de Janeiro: Ed. 34, 1994.

LEMOS, A. Jogos móveis locativos: Cibercultura, espaço urbano e mídia locativa. Revista USP, São Paulo, n. 86, p. 5465, jun./ago. 2010. Disponível em: < http://www.revistas.usp. br/revusp/article/view/13813>. Acesso em: 14 dez. 2014.

LÉVY, P. As tecnologias da inteligência: o futuro do pensamento na era da informática. Rio de Janeiro: Ed. 34, 1993.

MARASCHIN, C.; AXT, M. O enigma da tecnologia na formação docente. RIBIE 98, CONGRESSO DA REDE IBEROAMERICANA DE INFORMÁTICA EDUCATIVA, 4., 1998, Brasília. Anais... Brasília: [s.n.], 1998. Disponível em: <http://www.ufrgs.br/lelic/files gerenciador_de_arquivos/artigo/1998/56/1373312925anais_ de_congresso_o_enigma_da_tecnologia_na_formacao_ docente.pdf>. Acesso em: 20 dez. 2014.

MONT'ALVERNE, A. Jogos móveis de localização: uma proposta de classificação. Contemporânea, [online], v. 10, n. 1, 2012. Disponível em: <http://www.e-publicacoes.uerj.br/ojs/ index.php/contemporanea/article/view/3033>. Acesso em: 14 dez. 2014.

SANTOS, M. A natureza do espaço: técnica e tempo, razão e emoção. 4. ed. São Paulo: EDUSP, 1997.
SATO, A. K. O; CARDOSO, M. V. Além do gênero: uma possibilidade para a classificação de jogos. In: SBGAMES'08: GAME \& CULTURE TRACK, 7., 2008, Belo Horizonte. Proceedings... Belo Horizonte: [s.n.], 2008. Disponível em: $<$ https:/www.researchgate.net/publication/228877818_Alem_ do_genero_uma_possibilidade_para_a_classificacao_de jogos>. Acesso em: 12 dez. 2014.

SIMONDON, G. Du mode d'existence des objets techniques (1958). Paris: Aubier, 2008.

SIMONDON, G. Imaginación e invención. Buenos Aires: Cactus, 2013.

STENGERS, I. A invenção das ciências modernas. São Paulo, Ed. 34, 2002.

SQUIRE, K. From content to context: videogames as designed experience. Educational researcher, v. 35, n. 8, p. 19-29, 2006.

VARELA, F. Conhecer: introdução à ciência cognitiva. Lisboa: Instituto Piaget, 1994.

VARELA, F; THOMPSON, E; ROSCH, E. A mente incorporada: ciências cognitivas e experiência humana. Porto Alegre: Artmed, 2003.

Recebido em: 25 de fevereiro de 2015 Aceito em: 7 de julho de 2016 